\title{
Os Processos de Socialização dos Sucessores em Empresas Familiares: O desafio de CONSTRUIR A tRANSIÇÃo MULTIGERACIONAL
}

\author{
The Processes of Socialization of Heirs in Familyowned \\ Companies: the challenge of constructing the multigenerational
}

transition

\author{
Ana Luiza Albuquerque Cruz \\ Pesquisadora do Núcleo de Estudos Organizacionais e Sociedade e da Betania Tanure Associados. Universidade Federal de Minas \\ Gerais. Belo Horizonte, MG. Brasil. E-mail: analuiza_ac@yahoo.com.br
}

Janete Lara de Oliveira

Professora Adjunta da Universidade Federal de Minas Gerais.Belo Horizonte, MG. Brasil. E-mail: janetelara@face.ufmg.br

\section{Resumo}

No âmbito de uma empresa familiar, a literatura reconhece que a interação entre família e empresa é uma das principais dimensões constituintes e influenciadoras das dinâmicas dessas organizações, sobretudo, do processo sucessório. Este trabalho tem por objetivo analisar o processo de socialização de membros de uma família empresária e sua influência na constituição da dinâmica do processo de sucessão. Para tanto, adotou-se uma abordagem qualitativa apoiada na técnica do estudo de caso realizado em uma empresa do setor de drogaria e varejo que atua há mais de cem anos na região metropolitana de Belo Horizonte. A partir das entrevistas realizadas com os sujeitos pesquisados, é possível observar que a inserção precoce do herdeiro-sucessor na dinâmica da empresa possibilitou que ele se projetasse como o guardião dos valores familiares, portador de competências reconhecidas externamente, depositário do legado e responsável pela continuidade da empresa da família. Todas essas capacidades contribuíram para legitimar os herdeiros-sucessores no processo de sucessão da empresa pesquisada.

Palavras-chave: Organização Familiar. Sucessão. Socialização.

\section{Abstract}

In the context of a family owned company, the general literature recognizes that the interaction between the family and the company is one of the main constituting and influential dimensions of the dynamics within these organizations in regards to the succession process. The main objective is to analyze the process of socialization between members of a business family and their influence in the dynamic constitution of the succession process. For such, a qualitative approach was adopted based on the technique of case study, conducted in a company in the pharmaceutical and retail sector with more than 100 years of operations in Belo Horizonte. From the interviews conducted with the researched subjects it was possible to observe that the early insertion of the successor-heir in the company dynamics allowed for him to be projected as the guardian of the family values, bearer of externally recognized competencies, depositary of the legacy and responsible for the continuity of the family. All of these capacities have contributed to legitimize the heir-successors in the process of succession of the researched company.

Keywords: Family Owned Business Organization. Succession. Socialization. 


\section{INTRODUÇÃo}

No âmbito de uma empresa familiar, a dimensão afetivo-emocional que permeia as relações intrafamiliares $e$ as relações família-empresa apresenta grande capacidade de influenciar as relações no âmbito de toda a organização, como enfatiza a literatura sobre empresas familiares. A família, comumente, aparece como a mediadora entre o indivíduo e a sociedade, constituindo a instância primária de socialização. Posteriormente, ela aparecerá também como uma instância influenciadora das relações estabelecidas entre os membros da família e a empresa, pois, desde a infância, os indivíduos convivem com e entre essas duas instâncias. Contudo, a empresa também constitui uma importante instância de socialização, na qual a noção de comprometimento com a continuidade do negócio se mistura à ideia de continuidade da própria família.

A problemática da sucessão é reconhecida teoricamente como um dos momentos mais delicados por que passa a empresa familiar, não só por envolver os aspectos formais e legais do processo, mas, especialmente, por revolver os aspectos mais profundos e delicados das relações familiares. Tendo a sucessão como a questão central e considerando as especificidades que marcam o contexto das empresas familiares - a coexistência e a interação entre as relações familiares e de trabalho - este artigo teve como objetivo compreender como as socializações dos membros de uma família empresária influenciam o processo sucessório. Para tanto, optou-se por aprofundar o entendimento de como se deu o processo de socialização dos herdeiros sob o ponto de vista de diferentes atores que, de alguma forma, vivenciaram esse processo.

Esta pesquisa se justifica pela possibilidade de, ao abordar a problemática da sucessão, concentrar a discussão em outros aspectos relacionados aos processos de socialização dos herdeiros que também são fundamentais para a continuidade da família à frente da gestão, mas que ainda são pouco explorados pela literatura. Pesquisa recente realizada por Borges, Lescura e Oliveira (2012) conclui por uma significativa produção brasileira na temática de empresas familiares, particularmente na temática de sucessão, mas não foram encontrados trabalhos com o recorte apresentado por esta pesquisa. Esta pesquisa buscará compreender, na perspectiva dos próprios sucessores, como se dá o processo de construção da legitimidade do herdeiro-sucessor e que elementos aparecem como constitutivos da dinâmica que, para além dos aspectos legais e formais, tornam o herdeiro-sucessor legítimo aos olhos da organização.

Foi utilizada uma abordagem qualitativa que permitiu aprofundar os significados das construções, ações e relações humanas, a partir da voz dos atores envolvidos nos processos de socialização e de sucessão da Drogaria Araujo, uma empresa do setor de drogaria e varejo, somando mais de cem anos de tradição localizada na região metropolitana de Belo Horizonte. O presente artigo está estruturado em quatro partes, além desta introdução. Na seção seguinte, discute-se a empresa familiar como lócus de pesquisa e base teórica que norteia a discussão sobre socialização. Posteriormente, serão apresentados os caminhos metodológicos percorridos, a análise das informações coletadas e a discussão dos resultados e, por último, alguns aspectos que foram considerados particularmente relevantes neste trabalho, especialmente com o objetivo de contribuir para estudos futuros.

\section{2 família e Organização: trajetórias QUE SE CRUZAM}

A família, conforme salientam Davel e Colbari (2000, 2003), pode ser compreendida como a base da concepção naturalista e historicista. A primeira entende a família como entidade anterior a qualquer forma de sociedade e configurada natural e biologicamente. A segunda concepção, por sua vez, trata a família como uma realidade histórica, inserida numa dinâmica social, econômica e cultural, compreendendo-a como um fenômeno social.

Partindo da abordagem historicista, Engels (1975, p. 91) afirma que a família constitui um fenômeno social $e$ "[...] deve progredir na medida em que progrida a sociedade, que deve modificar-se na medida em que a sociedade se modifique; como sucedeu até agora. A família é produto do sistema social e refletirá o estado de cultura desse sistema". Dessa forma, faz-se necessário enfatizar as singularidades do grupo familiar, uma vez que cada família assimila, de forma particular, o contexto no qual se desenvolve e, ao mesmo tempo, (re-)constrói o mundo social a partir das suas singula- 
ridades. Como uma instância de socialização privilegiada, ela atua nos sentido de oferecer aos indivíduos em formação padrões de referência sobre os quais eles formarão sua personalidade e visão de mundo. Como salientam Davel e Colbari (2000, p. 46),

[...] a família, vinculada ou separada da esfera de produção, sempre foi instância privilegiada de socialização e de controle social, constituindo-se como referência básica no desencadeamento de processos motivadores $e$ condicionadores da inserção dos indivíduos na atividade produtiva.

A família atua, então, como lócus da primeira socialização que um indivíduo experimenta. A socialização corresponde, de acordo com Berger e Luckmann (2004, p. 175), a uma "[...] ampla e consistente introdução de um indivíduo no mundo objetivo de uma sociedade ou de um setor dela". O indivíduo, ainda na infância, experimenta a socialização primária, a partir da qual ele se tornará membro da sociedade. $\mathrm{O}$ indivíduo nasce em uma estrutura social objetiva, dentro da qual encontra os outros significativos (associados à função materna e paterna) que estabelecem a mediação entre ele e o mundo social objetivo.

A família, pelo seu lugar especial, apresenta ao indivíduo aspectos do mundo que estão em consonância com a localização da própria família na estrutura social. Nesse processo de socialização, a criança absorve essa percepção "[...] com uma coloração particular que lhe é dada por seus pais" (BERGER; LUCKMANN, 2004, p. 176). No caso das crianças provenientes de uma família empresária, tem-se um contexto com elementos específicos, o que as diferencia das crianças que não experimentam uma realidade em que família e negócio se misturam. No caso de um indivíduo que nasce no contexto de uma organização familiar, a empresa lhe é apresentada como parte essencial do mundo em que ele irá habitar. Dessa forma, o indivíduo "[...] aprende que é aquilo que é chamado [e isso] implica uma localização social determinada. Isso significa dizer que as identificações realizam-se, assim, em horizontes que implicam um mundo social específico" (BERGER; LUCKMANN, 2004, p. 177). Por vezes, o nome e sobrenome da criança implicam uma localização social como herdeiro dos negócios da família e guardião do legado de seus antepassados e, ao receber essa identificação, a criança carrega consigo atribuições do lugar que ocupa.

Berger e Luckmann (2004) ressaltam que na socialização primária não há problemas de identificação, pois não há possibilidades de se escolher outros significativos, fazendo com que a criança se identifique automaticamente com eles. Nas palavras dos autores "[...] temos que nos arranjar com os pais que o destino nos deu" (BERGER; LUCKMANN, 2004, p. 180. No caso da família empresária, a criança identifica-se como sendo parte da empresa e, muitas vezes, sente-se responsável pela continuidade dos negócios.

Os conteúdos interiorizados na socialização primária fornecem aos indivíduos "[...] programas institucionalizados para a vida cotidiana [...]" que acabam por contribuir para a construção da identidade do indivíduo, separando-os dos outros (BERGER; LUCKMANN, 2004, p. 181). Assim, esses programas se incumbem de explicitar aos indivíduos as formas de comportamento $e$ as posturas relacionadas às ações $e$ papéis desempenhados cotidianamente.

O processo de socialização permeia toda a vida do individuo, mas a socialização primária é retida em níveis do consciente e do inconsciente do indivíduo, voltando frequentemente à sua memória. Berger e Luckman (2004, p. 184) falarão então da socialização secundária, que corresponde "[...] à interiorização de 'submundos' institucionais ou baseados em instituições". Essa etapa corresponde aos processos de socialização subsequentes à socialização primária, nos quais esses submundos se apresentam como realidades parciais, nas quais os indivíduos absorvem conhecimentos específicos enraizados ou não na divisão social do trabalho. Os processos correspondentes à socialização secundária partem do pressuposto de que uma socialização primária já ocorreu, ou seja, que os indivíduos já apresentam uma subjetividade delineada. Tal pressuposto, na verdade, pode configurar-se como um problema, na medida em que novas realidades podem surgir de forma contraditória, complementar, totalmente nova ou diferente da realidade previamente interiorizada, competindo com ela nos novos significados que o indivíduo irá produzir. Processos pedagógicos, por exemplo, constituem formas de integrar os diferentes corpos de conhecimento e conferir aos novos um maior tom de realidade, permitindo 
ao indivíduo significar novas realidades. (BERGER; LUCKMANN, 2004)

Diferentemente do que ocorre na socialização primária, na socialização secundária, a identificação integral entre os indivíduos pode ser dispensada, sendo necessário apenas o mínimo de identificação mútua incluída na comunicação entre os seres. Tal fato confere a esse processo formalismo $e$ anonimato, atribuindo ao conteúdo internalizado menor inevitabilidade subjetiva. Por conseguinte, aquilo que é apreendido torna-se menos real e, assim, o conhecimento é mais facilmente colocado à prova. Ao indivíduo confere-se maior oportunidade de questionamento. (BERGER; LUCKMANN, 2004)

Como a socialização secundária se soma aos outros tipos de interações sociais que o indivíduo experimenta ao longo da vida em contato com grupos secundários, que não apenas a família, a organização constitui um tipo de espaço institucional privilegiado de socialização (BERGER; LUCKMANN, 2004). Dessa forma, a organização familiar se configura como uma importante instância de socialização, uma vez que os membros da família empresária convivem desde a infância com a influência das questões empresariais na dinâmica da família. Embora a dimensão familiar seja fundamental para se compreenderem as relações sociais que se estabelecem em organizações empresarias de base familiar, a situação inversa também pode ocorrer, isto é, a empresa pode influenciar as dinâmicas familiares.

Para Lima, Pimentel e Soares (2008, p. 218), “[...] a interiorização dos papéis familiares poderia se apresentar mais eficazmente também pela responsabilidade dos indivíduos como aquilo que será o sustento dos membros da família". Dessa forma, esse argumento, usado pelos pais sobre os filhos, constrói uma realidade na qual o filho é levado a se comprometer com os negócios da família desde cedo. Nesse caso, a empresa está constantemente presente na socialização dos filhos já em sua instância primária.

Ainda na infância, os membros da família empresária geralmente observam a centralidade que os pais conferem aos negócios da família, associada a uma rotina e a um contexto que vincula os membros daquela família aos negócios da empresa. No entanto, a socialização secundária também pode apresentar novas e diferentes oportunidades, o que pode gerar conflitos na vida dos filhos-sucessores. A possibilidade de uma vida distante dos negócios da família, ou o questionamento aos pais sobre a maneira de condução os negócios podem trazer inúmeros conflitos psicológicos e familiares para esses indivíduos.

No caso das famílias empresárias, na maioria das vezes, a socialização incorpora a ideia de comprometimento com a continuidade do negócio da família. Dessa forma, faz-se necessário discutir a problemática da sucessão, que é considerada pela literatura um eixo fundamental para a compreensão das organizações familiares e uma das situações mais delicadas que esse tipo de organização vivencia, sobretudo, por ser preponderante para sua continuidade. Como ressalta Machado (2008, p.186), a complexidade desse processo vai além do preparo dos sucessores e do planejamento do processo, por refletir a "[...] existência de influências sociais e culturais que estabelecem fronteiras invisíveis [...]" entre o indivíduo, a família e a empresa.

Para além de se buscar compreender a sucessão por meio de modelos teóricos, a presente pesquisa caminha na tentativa de considerar as constantes interações entre indivíduos, família e empresa, uma vez que essas interações são elementos intervenientes no processo sucessório. Dessa forma, concorda-se com Landsberg (1999) quando ele considera a sucessão um processo e, não, um evento que se formaliza no momento em que a propriedade e a gestão, não necessariamente ao mesmo tempo, serão repassadas ao sucessor, podendo este ser um membro da família ou um profissional de mercado, conforme salientam Chittor e Das (2007). Acrescenta-se ainda que a sucessão pode ocorrer de forma gradativa e planejada ou por meio de um processo inesperado ou repentino quando ocorre algo que afasta o dirigente do cargo (LEONE, 2005). Ressalta-se que a sucessão é aqui entendida, não apenas no âmbito da propriedade, mas, sobretudo, na transferência da gestão da empresa para a geração futura ou para profissionais não membros da família.

Nesse contexto, a sucessão é uma jornada construída pela família, pelo indivíduo e pelos membros da organização e envolve a definição do destino dos indivíduos, alimentando ou encerrando sonhos e expectativas compartilhadas, construídos, às vezes, ao longo de décadas. Dessa forma, a ideia da sucessão já pode ser identificada antes mesmo de os sucessores se inserirem formalmente nos negócios. No contexto de 
uma família empresária, os pais, ao criarem seus filhos, por vezes os levam a se reconhecerem e se identificarem como proprietários de uma empresa influenciando-os a seguirem os caminhos dos pais, com o objetivo de perpetuar os negócios da família. Muito frequentemente os filhos são apresentados, ainda na infância, ao universo da empresa e da família e, ao perceberem os papéis dos pais, irão repetir essa lógica. As brincadeiras tenderão a reproduzir os cenários que remetem à empresa e à profissão do pai e são comuns na infância dessas crianças. Assim, os membros de uma família empresária são simultaneamente submetidos a uma dupla dinâmica social: as relações no âmbito familiar e o universo do trabalho. (DAVEL; COLBARI, 2000)

A sucessão envolve, assim, múltiplas esferas que não podem ser deixadas de lado quando tal processo se aproxima, dado que o afastamento do predecessor das atividades de gestão requer ações cuidadosas para auxiliá-lo nesse difícil momento de desligamento e para criar um ambiente no qual o sucessor possa assumir o cargo, desempenhar o seu trabalho e construir sua legitimidade. O planejamento sucessório e a profissionalização surgem como instrumentos para nortear a família e a empresa, bem como para minimizar conflitos. Assim, a família, ao se propor pensar a sucessão, acaba por identificar, compreender e construir o seu próprio plano de transição multigeracional (LAMBRECHT, 2005). Tendo a sucessão como pano de fundo, observa-se que a própria forma como os membros da família são inseridos na empresa pode indicar os caminhos pelos quais a sucessão é construída. Nesse sentido, compreender os processos de socializações dos herdeiros é também um modo de refletir sobre alguns dos desafios advindos do processo sucessório apresentados à organização familiar, uma vez que a socialização dos herdeiros pode ser um dos fatores que influenciam, principalmente, a continuidade da organização. Assim, visando contribuir para a ampliação de nossa compreensão acerca de como ocorrem os processos de socializações dos membros de uma família empresária e como esses processos influenciam a sucessão, alguns caminhos foram percorridos por esta pesquisa e serão apresentados nas sessões seguintes.

\section{Caminhos Percorridos}

Esta pesquisa buscou compreender a realidade social da organização estudada a partir do ponto de vista dos atores diretamente envolvidos no processo social, neste caso, o sucedido, os herdeiros possíveis sucessores, membros da família empresária e da própria empresa. Este estudo se apresenta como uma pesquisa de natureza qualitativa $e$ interpretativa, por buscar compreender os significados atribuídos à determinada experiência social, na perspectiva da interpretação conferida pelos atores envolvidos no fenômeno social sob investigação. O que os pesquisadores buscam é entender e interpretar os "[...] fenômenos em termos dos significados que as pessoas a eles conferem". (DENZIN; LINCOLN, 2006, p. 17)

A fim de evidenciar algumas dimensões que estão presentes nos processos de sucessão e de socializações, utilizou-se a técnica do estudo de caso, dado que ela permite um exame intensivo de um ou mais objetos de estudos, a fim de promover o mais profundo e completo entendimento do objeto (YIN, 2005). Essa técnica possibilita ainda imersão do pesquisador e ampla possibilidade de compreensão de um ou de poucos casos, considerando as suas especificidades e complexidades (STAKE, 1994). Para a presente pesquisa, o estudo de caso único apresentou-se como uma técnica adequada por permitir uma investigação em profundidade dos processos de socializações e sucessão, favorecendo a emergência de uma multiplicidade de elementos explanatórios relacionados à problemática em questão.

O corpus da pesquisa foi constituído por membros da família e da empresa, o sucedido, e por herdeiros prováveis sucessores. Ressalta-se que o processo sucessório já ter ocorrido foi um critério que norteou a seleção do caso estudado, além, naturalmente, da disponibilidade apresentada pela empresa para participar da pesquisa. A empresa pesquisada, a Drogaria Araujo, pertence ao setor de drogaria e varejo, foi fundada há 105 anos e atua em toda a região metropolitana de Belo Horizonte.

Foram realizadas 11 entrevistas, sendo uma com o presidente, membro da terceira geração, cinco com 
antigos funcionários da empresa, não pertencentes às famílias proprietárias, uma com um publicitário parceiro ao longo de 11 anos, três com membros da quarta geração e uma com um membro da segunda geração. De forma complementar às entrevistas, foram coletados dados secundários da empresa estudada, dentre os quais se destacam recortes de jornais, informações disponibilizadas no site, artigos e outras publicações acadêmicas relacionadas à empresa em questão. Para comemoração do centenário da empresa, em 2006, foi produzido um livro, contendo a história da empresa desde a fundação e ricamente ilustrado com fotos de época, que não chegou a ser publicado, mas foi disponibilizado aos pesquisadores e constituiu uma importante fonte de informação.

No que se refere ao processo de categorização, foram definidos a priori alguns eixos temáticos mais amplos no intuito de nortear o desenvolvimento da análise: socialização e sucessão. A partir desses eixos temáticos, surgiram algumas categorias de análise, quais sejam: a família e a empresa como instâncias de socialização; o preparo dos sucessores; o planejamento sucessório, conflitos entre gerações; formas de inserção na empresa e princípios norteadores do processo sucessório.

Para a análise das entrevistas utilizou-se a técnica de análise de conteúdo, que permite acessar as "[...] realidades subjetivas das representações simbólicas" (RODRIGUES; LEOPARDI, 1999, p. 19). Buscou-se, assim, apreender o sentido atribuído pelos sujeitos a um determinado fenômeno, que se concretiza na prática social e se manifesta a partir das representações cognitivas, valorativas, sociais e emocionais, de forma contextualizada (FRANCO, 2003). Considerando as várias modalidades de análise de conteúdo (MINAYO, 2008), adotou-se neste estudo a análise categorial ou temática, que é descrita por Bardin (1977) como o processo de análise do texto a partir de unidades categorizadas e agrupadas analogicamente em relação aos eixos temáticos. A análise compreendeu as três fases operacionais apresentadas pela autora. A pré-análise correspondeu à etapa de sistematização do plano de análise, contando com a constituição do corpus, representado, neste caso, pelo conjunto das entrevistas. A fase da exploração do material envolveu o tratamento dos dados por meio da codificação dos trechos de entrevistas empregados na análise. A terceira etapa correspondeu à interpretação inferencial dos resultados, estabelecendo-se as relações entre as análises empíricas e as questões que nortearam a pesquisa.

\section{Sucessões e Socializações na Drogaria Araujo}

A Drogaria Araújo localiza-se na região metropolitana de Belo Horizonte, Minas Gerais, e soma 105 anos de história e tradição. A origem da Drogaria Araújo remete à história de seu fundador, que se mudou para a capital mineira para atuar como balconista e manipulador da então Pharmácia Mineira, que passa a ser de sua propriedade em 1913 e tem seu nome alterado para Drogaria Araujo, em 1921. No início da década de 1930, inicia-se a inserção da segunda geração na empresa, com a entrada do filho do fundador, ainda menino, executando atividades simples e rotineiras. Aos poucos ele vai conquistando espaço, sendo formalmente contratado como funcionário da empresa e tornando-se braço direito do fundador e, em 1944, também proprietário do negócio. A entrada da terceira geração (neto do fundador) ocorre na década de 1960, quando ele inicia suas atividades na empresa da família, de forma similar a que seu pai havia galgado, primeiro, em funções mais operacionais e, gradativamente, se inserindo nas atividades administrativas da empresa. A década de 1970 é caracterizada como uma fase de expansão e de diversificação dos negócios marcada pela abertura de sete filiais, a inauguração da Agroveterinária, conduzida simultaneamente pela segunda e terceira gerações.

Em 1979, falece o filho do fundador e, em menos de dois meses, o próprio fundador. Com a morte do pai e do avô, o neto assume a presidência da Araújo e, posteriormente, nos anos 80 , seu irmão, atual presidente da empresa, entra também nos negócios da família depois de resistir às pressões anteriormente feitas pelo avô para se inserir na empresa e, após acumular alguns anos de experiência fora, sobretudo, no mercado financeiro. A partir desse momento, a Drogaria Araujo passa a ser conduzida simultaneamente pelos dois irmãos.

A década de 1990 marca o lançamento de um novo conceito para a Araujo, o de drugstore, redirecionando-a para o segmento de varejo. Nos anos 2000, a Araujo saltou de 12 lojas para 75 filiais, em 2006, 
e, atualmente, somam-se 110 lojas. No meio de toda essa expansão, em 2004, inesperadamente morre o então presidente da Drogaria Araujo. Além de uma nova estrutura societária devido à entrada de novos acionistas, seus herdeiros, seu falecimento marca mais uma transição, tendo assumido a presidência o irmão que viera juntar-se aos negócios nos anos 80 . Paralelamente à gestão atual, é possível perceber uma maior participação da quarta geração da família na empresa, alguns já inseridos nos negócios desde a adolescência $e$ assumindo cargos de diretoria e outros inseridos há menos tempo, mas já ocupando seus lugares. Em 2006, comemorou-se o centenário da empresa, uma sociedade anônima cujo controle acionário encontra-se nas mãos da família Araújo.

\subsection{As Socializações dos Membros da Família e o Processo Sucessório na Drogaria Araujo}

Em mais de 100 anos de história, ocorreram duas sucessões na Drogaria Araujo, e a análise desses momentos de transição é essencial para a compreensão da longevidade da empresa ao longo das gerações. De 1916 a 1979, a empresa se encontrava sob o comando do fundador. A partir de 1945, a gestão dos negócios da família é compartilhada com um dos filhos do fundador. No entanto, a transição de fato da primeira para a segunda geração não acontece, pois o filho falece precocemente, quando o seu pai ainda estava no controle do negócio. Nesse mesmo ano, morre também o fundador. Esse momento caracterizou o primeiro processo sucessório na Drogaria Araújo, quando, em 1979, a gestão foi repassada para um neto do fundador, inserindo a terceira geração no comando da empresa.

As razões que levaram à primeira sucessão na Drogaria Araujo corroboram a constatação de Leone (2005) de que esse processo pode se dar de forma inesperada e repentina. Diante de uma circunstância inesperada e da necessidade de dar continuidade ao trabalho dos antecessores, ocorre a primeira sucessão na Drogaria Araujo. Não houve um planejamento formal de quando e como seria feita a transmissão da propriedade e da gestão para as próximas gerações. A ausência de um planejamento sucessório formal corrobora a literatura que, comumente, ressalta a importância do planejamento para a condução do processo sucessório, embora não suficiente para que o processo seja bem-sucedido. Apesar do caráter inesperado e precipitado dessa sucessão, percebe-se que o neto já estava sendo preparado para assumir, no futuro, a gestão da Drogaria Araujo, o que pode ser confirmado pelo trecho a seguir.

Quando [o Eduardo] foi para a Araujo, o avô o colocou para fazer os serviços mais simples como varrer a loja. Como todo grande empreendedor faz com seus descendentes, queria que o neto aprendesse na prática o dia a dia da empresa, mesmo que isto pudesse parecer uma humilhação. (Depoimento no Livro do Centenário, p. 137,grifos das autoras do artigo)

Essas palavras nos remetem a outra forma de planejamento, mais informal, associado às diferentes formas que um processo de socialização pode assumir, sobretudo, no que tange à inserção das novas gerações nos negócios. Assim, a forma como o avô inseriu o neto na Drogaria fez com que sua escolha como presidente da empresa no momento da morte do pai e do avô fosse entendida como natural. O conhecimento do negócio adquirido por meio da vivência diária nas atividades-base da empresa foi o processo que legitimou o neto para assumir os negócios na ausência do pai e do avô, de forma tão repentina, sem inscrever nenhuma crise ou descontinuidade nas atividades.

O contexto em que ocorre a primeira sucessão na Drogaria Araujo permite discutir o planejamento como algo que vai além de prescrever critérios para a preparação dos sucessores e sucedidos. Permite também refletir sobre um planejamento que se inicia na infância dos herdeiros, na socialização dessas crianças em um mundo em que eles possam se localizar como possíveis sucessores e, posteriormente, na socialização desses herdeiros como membros de uma organização familiar. Essas formas de socialização implicitamente fornecem as diretrizes norteadoras do processo sucessório, configurando-se como um planejamento tácito, tal como se discutiu nos tópicos seguintes.

Identificaram-se três etapas relacionadas à inserção das gerações na Drogaria, a saber: identificação, entrada e formalização. A identificação retrata um primeiro momento no qual a empresa é apresentada à criança, que acaba se identificando como parte dela. A entrada refere-se ao momento em que o herdeiro começa a vivenciar o dia a dia dos negócios da famí- 
lia, início que se dá sem a existência de vínculos mais formais com a organização. A terceira e última fase envolve a formalização de vínculo com a empresa, seja como funcionário, seja como proprietário. Ao descreverem suas trajetórias de vida, os herdeiros relatam claramente sua passagem por esses três momentos. Pode-se dizer que a identificação, a entrada e a formalização são etapas que decorrem do processo de socialização primária e secundária pelo qual esses herdeiros passaram e constituem efetivamente o planejamento tácito do processo de sucessão nessa empresa, definindo quem poderia ser considerado um potencial sucessor.

As organizações familiares, como Lima, Pimentel e Soares (2008) ressaltam, apresentam processos peculiares de socializações, que vão além da transmissão de conhecimento relativos à esfera do trabalho (socialização secundária). Esses processos envolvem a introjeção de símbolos, valores, crenças, formas de fazer e de pensar relacionadas à esfera da família e à esfera do trabalho, que se mesclam. Em outras palavras, juntamente com a família, uma empresa se configura como um espaço por meio do qual os membros da família empresária interagem socialmente desde a infância.

Na Araújo, a socialização dos membros da família apresenta desde cedo a empresa como parte do mundo em que irão habitar, a localização social como herdeiros, os padrões de comportamentos esperados, a identificação como parte dos negócios da família, a entrada na empresa e a preparação dos prováveis sucessores são alguns dos percursos pelos quais as socializações se construíram e se constroem nessa família e nessa organização. A empresa compõe o mundo dos membros da família Araujo desde o início das suas vidas, tal como relata um dos entrevistados.

(01) A minha infância é interessante. Aqui a entrega [de mercadorias] era de bicicleta. Então, na hora que não tinha entrega, eu roubava a bicicleta para aprender a andar. E andava aqui na Avenida Afonso Pena mesmo, não tinha outro lugar não. (Entrevistado 5)

Comumente, quando um sujeito narra a sua infância, se espera que ele fale das coisas que marcaram este período da sua vida. Nesse caso, observa-se que o entrevistado relata sua infância de forma intimamente associada à empresa, um lócus quase tão importante quanto a casa da família. Ao descrever os primeiros anos de sua vida, ele relata que, até mesmo as atividades lúdicas, se desenvolveram no espaço da empresa. A presença constante da empresa na esfera familiar permite inferir que a empresa constitui um aspecto relevante da estrutura social da qual ele faz parte e, desde cedo, passou a se identificar como parte dos negócios da família.

A percepção do trabalho e das atitudes dos pais, somada à relação emocional que se estabelece durante a infância pode ser apontada como referências do processo de socialização, processo este que se dá em meio às construções em casa e à realidade na empresa. Nesse momento, o que é apresentado ao sujeito acaba por contribuir para a construção de sua identidade que, na infância, não se reconhece como algo separado de seus pais (BERGER; LUCKMANN, 2004). Dessa forma, ao passear com os filhos pela loja, o pai apresenta-lhes a empresa como um mundo do qual fazem parte e, ao permitir e incentivar que eles vivenciem essa realidade, esse pai os vincula diretamente aos negócios da família. Isso aparece claramente nas palavras do entrevistado.

(02) Não lembro exatamente o que, mas eu lembro que era pequena e a gente saiu em um sábado ou sexta à noite. Ele me chamou para ir com ele que a gente ia rodar, acho que umas 20 lojas, lacrando as máquinas de [refrigerante], porque a partir do dia seguinte tinha uma multa e (o pai) falou comigo que era uma missão muito importante e aí eu fui. Ficamos até de madrugada, sem abrir boca, nada, com aquele espírito gostoso de ajudar, de ver a empresa dando certo, crescer e tal. Então eu cresci com isso. (Entrevistado 1 - grifos das autoras do artigo)

É possível observar que, além de vivenciar o dia a dia do pai na empresa, esse sujeito sente-se como parte desse mundo quando o pai a convida para uma missão muito importante. A ideia de missão desperta na criança a fantasia e imaginação e, nessa brincadeira, ela sente que faz parte do processo e é importante. No entanto, ao se inserir nessa realidade, alguns padrões de comportamentos passam a ser vistos como adequados para aqueles que ocupam ou ocuparão uma posição ou um cargo dentro de uma empresa familiar e que, por sua vez, podem diferenciá-los dos demais membros da empresa. Pode-se perceber, pelas palavras de um entrevistado não membro da família, 
que existe uma pressão e uma cobrança maior sobre os membros da família.

(03) O negocio é deles, eles querem crescer a empresa, eles têm responsabilidade. Eles têm que ter a responsabilidade deles, não é só por dinheiro. 'Tem 105 anos esse negocio aqui, não vai ser na minha mão que eu vou quebrar $e$ fazer $\mathrm{m}$... tenho responsabilidade moral com a família de fazer esse trem funcionar, se funcionou assim antes'. (Entrevistado 8 - grifos das autoras do artigo)

Por essas palavras pode-se inferir que a localização social como herdeiros da Drogaria Araujo impõe sobre os membros da família inseridos nos negócios uma responsabilidade com o que foi construído ao longo de décadas. É possível afirmar, então, que essa localização social não apenas significa aceitar ou rejeitar os padrões de comportamentos requeridos por sua localização, pois ser herdeiro dos negócios da família, muitas vezes, significa ser guardião do legado de seus antepassados, um guardião do legado, sob o qual recaem exigências que requerem uma capacidade quase heróica, como se depreende do depoimento seguinte.

(04) Imagina só a família inteira depender de você. E não adianta em uma empresa familiar você ter a visão individualista, não adianta, a empresa quebra. A empresa está para você acima da sua vida, isso é uma empresa familiar de 105 anos. Você tem que querer muito. Tem que ter uma disciplina gigante. Você fala assim: 'Bacana, a turminha toda que passou ai fez crescer, e você foi naquele ditado: "Avô rico, pai nobre e filho pobre.' Então é o seguinte, você não quer viver isso, a responsabilidade toda da família está com você. Então a responsabilidade da minha mãe, dos meus irmãos, você carrega com você. E não é só o peso da sua família, é o peso das outras famílias. Porque para mim seria muito fácil entrar aqui dentro e pensar no meu e o dos outros que se exploda, só que isso não é continuidade. (Entrevistado 3 - grifos das autoras do artigo)

As fantasias de criança deixam de existir quando o herdeiro se insere formalmente nos negócios e sente o peso de se comprometer com a longevidade da empresa. Essa realidade muitas vezes se apresenta de forma dura, colocando o trabalho e a empresa acima da vida pessoal. O que implica sacrifícios, pressões e, por que não dizer, a condição de possível sucessor pode também se configurar como um fardo. Não é possível afirmar que os entrevistados membros dessa família percebam sua condição de herdeiros como um fardo; no entanto, as falas explicitam termos como o peso das outras famílias e acima da sua vida revelando que nem sempre é fácil para esses sujeitos vivenciar essa condição.

O comprometimento com aquilo que a família construiu há mais de um século é também observado na fala de um parceiro entrevistado.

(05) A influência do Modesto, o primeiro [fundador], sobre os netos, foi decisiva para que essa continuidade, essa sucessão permanecesse até hoje. (Entrevistado 11).

A transmissão de valores, de saberes - expressos pela palavra influência -, entre as gerações, é reconhecida como um elemento de coesão da família $e$ da empresa, pois, de acordo com esse entrevistado, o fundador da Drogaria Araujo plantou nas gerações seguintes a ideia da continuidade, de se preservar a unidade da empresa nas mãos da família. Diante da ausência de um planejamento formal e da constatação de que as sementes da continuidade foram lançadas, a entrada hoje já da quarta geração mostra que as sementes plantadas desde o fundador continuam vigorosas.

A responsabilidade com aquilo que foi é e será o sustento da família também compõe a fase de interiorização desses papéis familiares e se apresenta, no caso da Drogaria Araújo, como um argumento utilizado pelos pais para levar os filhos a assumirem o comprometimento com os negócios da família.

(06) Na hora que eu estava engrenando minha carreira lá [outra empresa que trabalhava], ele [o pai] me convidou para vir, porque era o ano do Centenário. E ele conversou comigo, e eu em uma dúvida danada, eu também sou apaixonada pela [outra empresa], acho um modelo de empresa admirável. E eu: 'Meu Deus, e agora?'. E ele me falou 'Filha, olha, essa empresa é nossa, a gente tem que continuar ela, vem me ajudar?. Na hora que ele me falou isso, eu disse: é claro que eu vou, e aí eu vim". (Entrevistado 1 - grifos das autoras do artigo) 
Quando o entrevistado diz claro que eu vou, pode-se perceber que já está enraizado nele esse compromisso com o negócio, pois, desde a infância, a Drogaria faz parte da sua vida, seja pelo trabalho de seu pai, pelo sustento da família, pela vivência da empresa como espaço de lazer, vivenciado nos momentos de estar ao lado do pai, muitas vezes, ausente em casa, ou por representar uma extensão de seu lar. Quando o pai argumenta essa empresa é nossa, ele reforça o que o filho vem aprendendo esses anos todos: o lugar dele no mundo está relacionado à empresa da família.

Outro percurso destacado pelos entrevistados foi a forma de inserção nos negócios da família. Muitas vezes, esse início se dá informalmente, entre os intervalos da escola, ou nos períodos de férias, como retrata um entrevistado.

(07) Meu pai, todas as minhas férias, me trazia para trabalhar aqui. Férias para mim era trabalhar aqui na Araujo. Eu gostava, não era castigo. Era prazer. Então eu vinha trabalhava, atendia no balcão. (Entrevistado 4)

Nessa fase, ainda não é definida uma função específica a ser executada ou um cargo a assumir. Observa-se que os membros da família, em intervalos da sua rotina, simplesmente vão para a empresa e lá começam a se inteirar de assuntos do seu interesse, a participar de algumas atividades. Não há, a princípio, um vínculo ou uma obrigação explicita com a empresa, como se pode observar em outra fala.

(08) Fui fazendo estágio fora, eu fiz estágio na câmara de comércio de Portugal, fiz na TV Bandeirantes, fui trainee no INDG, trabalhei no Itaú Personalité e, de vez em quando, em algumas férias, eu voltava para cá, e ficava sentindo o batente aqui. (Entrevistado 2)

Mesmo sem estabelecer um vínculo formal com a empresa desde a infância ou a adolescência, os herdeiros foram se inserindo desde cedo, realizando atividades mais simples nos primeiros anos, galgando posteriormente outras funções e posições dentro da empresa, ilustrando claramente a ideia de hierarquia, conforme explicitado no trecho seguinte.

(09) Eu, como filho do fundador, eu comecei como lava-vidro. Comprava vidro em um depósito que tinha aqui na Pedro II, lavava e punha para encher de remédio. Passei para o balcão, passei a gerente, fui gerente de todas as filiais e, depois, diretor. (Entrevistado 5)

É interessante observar que a prática de facilitar a inserção das gerações na rotina dos negócios ainda na infância permanece ao longo das gerações. No momento de uma das entrevistas, foi relatado que os membros da quinta geração já estão acompanhando os pais em algumas atividades da empresa.

(10) Então, tem um clima gostoso, uma harmonia muito gostosa que hoje os filhos dos diretores já estão começando a vir nas férias e adoram também. (Entrevistado 1)

Ao se inserirem na empresa da família e passarem a se relacionar com os membros que lá já estão, eles se deparam com uma realidade lhes coloca papéis e atribuições em função da posição que ocuparão naquela estrutura, filhos dos donos e futuros donos do negócio.

Na socialização secundária, o indivíduo experimenta outros tipos de interações sociais ao entrar em contato com grupos secundários que não apenas a família. Nesse sentido, uma empresa também constitui uma instância de socialização secundária e, dessa forma, os membros que a compóem configuram-se como outros significativos. Nesse momento, o contraponto com o outro se torna um elemento de autoconhecimento de identificação consigo mesmo. Percebe-se, então, a construção de uma identidade em relação à generalidade, identidade esta subjetivamente apreendida como constante e composta por todos os papéis e atitudes interiorizados e pela autoidentificação. (BERGER; LUCKMANN, 2004)

Após ter experimentado desde a infância a convivência com a Drogaria Araujo, chega para os herdeiros o momento de assumir explicitamente um compromisso com o que a família vem construindo ao longo de décadas. Em alguns casos, esse momento contou com um incentivo dos pais, como conta um entrevistado.

(11) E aí o meu pai me perguntou se já não era hora de vir para cá porque já tinha aprendido fora e estava precisando de gente aqui dentro e se me interessava. (Entrevistada 2 - grifos das autoras do artigo)

As palavras escolhidas pelo pai permitem inferir que há um desejo desse pai de que os filhos efetiva- 
mente façam parte da empresa, que se insiram formalmente e sejam também responsáveis pela condução dos negócios. O argumento do pai reforça o que foi ensinado a esses filhos desde a infância: a empresa é parte do seu mundo e isso implica uma localização social como herdeiro e responsável pela continuidade do negócio. Esse papel familiar aparece tão internalizado pelo herdeiro entrevistado que ele não tem como dizer não, pois se sente responsável e comprometido com a continuidade dos negócios da família. A decisão de vir para trabalhar ali aparece, assim, como desfecho de um processo de construção que ocorreu ao longo de toda a vida desse indivíduo, demonstrando que as etapas de identificação e posterior inserção começam a se desenvolver ainda na infância.

Para os envolvidos nos processos de socializações, toda essa construção não é percebida como impositiva ou como uma pressão. Eles cresceram tendo a empresa sempre presente e aprenderam desde pequenos os seus papéis, internalizados como algo natural, como se pode observar pela fala a seguir.

(12) É uma coisa que eu não sei explicar, às vezes, parece que a gente é meio direcionado, mas nunca sofri nenhuma pressão que eu tinha que vir trabalhar aqui, foi uma coisa muito, muito tranquila. (Entrevistado 2 - grifos das autoras do artigo)

Os entrevistados reconhecem que há um direcionamento, mas não o veem como uma pressão, reforçando a ideia apresentada por Berger e Luckmann (2004) de que, na socialização primária, não há problemas de identificação, pois a criança se identifica automaticamente com os pais e com o mundo que eles lhe apresentam. Essa realidade é colocada aos filhos de acordo com a percepção desses pais que estabelecem, por exemplo, o que é certo e errado e, nesse processo, as crianças interiorizam essas regras como algo dado, definido ou, até mesmo, definitivo. É essa interiorização que confere o caráter natural às construções estabelecidas pelos pais. Observa-se, contudo, uma contradição. Apesar de considerarem natural o direcionamento feito por seus pais no sentido de os inserirem na empresa e de não interpretarem isso como uma pressão ou imposição, é possível perceber que não existe a intenção de reproduzir esse mesmo processo com as gerações futuras.
(13) Foi natural. Mas hoje não faço isso com o meu filho, não faço isso com o meu filho de jeito nenhum, porque eu acho que a gente tem que dar o direito do outro escolher. E sinceramente eu não tive muita opção não, eu fui meio impelido, meio guiado a trabalhar na Araújo. (Entrevistado 3 - grifos das autoras do artigo)

As falas desse entrevistado novamente nos remetem à Berger e Luckmann (2004, p. 181), quando enfatizam que "[...] a socialização primária faz parecer como necessidade o que de fato é um feixe de contingência, dando sentido ao acidente que é o seu nascimento". A construção estabelecida por esses pais de que esse entrevistado é um herdeiro e como tal deve tomar conta do negócio é interiorizada por ele com um valor definitivo, sendo que, na verdade, é resultado de uma construção e justamente por isso pode ser reconstruída. Ser filho do dono é apenas uma contingência apresentada ao indivíduo como um fato que implica uma série de ações predefinidas, como assumir uma empresa da família, por exemplo. Na socialização secundária, contudo, há espaço para questionamento de novas realidades que se lhe apresentam.

O conhecimento e a vivência dos herdeiros em todas as áreas da empresa aparecem como uma condição para sua capacitação, pois permite o desenvolvimento de uma visão mais ampla, baseada na acumulação das experiências que tiveram ao transitar pelos diferentes setores e funções do negócio.

(14) Eu sempre me preparei em diferentes setores para tentar ter o máximo de bagagem para ter competência para assumir alguma coisa aqui. (Entrevistado 2)

Além desse conhecimento do negócio, a experiência fora da Araujo e a competência técnica são valorizadas e reconhecidas como elementos fundamentais na construção da legitimidade dos sucessores, reforçando a ideia defendida por Landsberg (1999) de que a preparação e o aprendizado dos herdeiros sucessores são dimensões importantes a serem consideradas no processo sucessório. 


\section{Considerações Finais}

Este estudo analisou o processo de socialização de herdeiros sucessores no âmbito de uma empresa familiar e buscou compreender como a socialização primária e a secundária, realizadas por meio da criação de mecanismos de inserção e identificação dos herdeiros com a empresa desde a infância e a preparação dos prováveis sucessores, são questões relevantes na compreensão da dinâmica de uma empresa familiar.

Um aspecto relevante identificado neste estudo foi a participação da empresa como instância socializadora dos sucessores desde a infância. A interação indivíduo-empresa se fez muito presente ao longo da socialização desses sucessores e, dessa forma, a cultura e os valores da família possibilitaram a esses sucessores se identificarem como parte dos negócios da família $e$, portanto, comprometidos com a sua continuidade. Nesse sentido, os filhos foram socializados tendo como referência o trabalho realizado por seus pais e avós, desde a fundação da empresa, e se acostumaram, já na infância, com o universo dos negócios. Ainda, no interior da família, já perceberam os papéis dos pais e, muitas vezes, se identificam com essa lógica, pois a rotina os vinculava diretamente aos negócios da família. A empresa, então, habitualmente tida como uma instância de socialização secundária invade também o espaço da socialização primária, misturando-se ao universo que é comumente restrito à família.

A inserção precoce herdeiro-sucessor nos negócios da família exerceu um papel particularmente importante no processo de socialização desse indivíduo. Quanto aos elementos constitutivos do processo de legitimação do herdeiro-sucessor, quatro papéis aparecem como fundamentais na construção desse reconhecimento e estão associados a sua capacidade de se estabelecer como: (i) guardião dos valores familiares; (ii) portador das competências necessárias para o exercício do cargo; (iii) depositário do legado da família e; (iv) responsável pela continuidade dos negócios da empresa (fig.1). A constatação de que a construção da legitimidade de herdeiros-sucessores alicerça-se em sua capacidade desempenhar esses quatro papéis, aos olhos dos membros da organização, pode ser apontada como uma importante contribuição desta pesquisa $e$ um aspecto a ser (re)avaliado por pesquisas futuras.

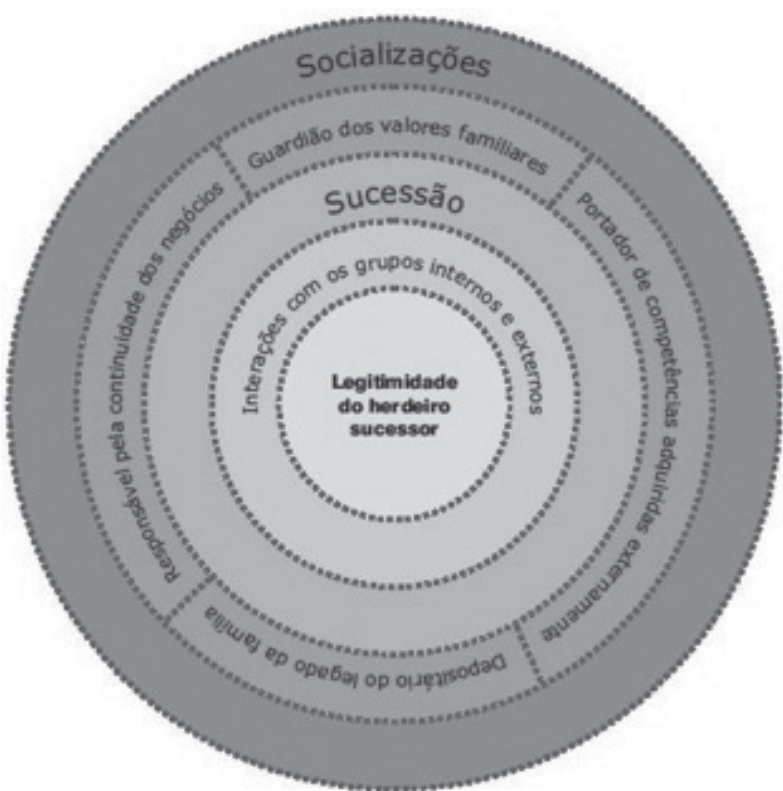

Figura 1: O processo de construção da legitimidade do herdeiro-sucessor

Fonte: Elaborada pelas autoras deste artigo

Foi possível evidenciar empresa estudada que os processos de identificação e de posterior inserção dos herdeiros não são vivenciados como uma pressão, apesar de os sujeitos reconhecerem que há um direcionamento, reforçando a ideia apresentada por Berger e Luckmann (2004) de que, na socialização primária, as identificações são imediatas. Herdeiros de negócios geralmente crescem tendo a empresa muito presente e aprendem desde pequenos quais são os papéis que supostamente devem desempenhar, internalizando-os como naturais. Os conteúdos interiorizados nessa etapa acabam por contribuir para a construção da identidade desses indivíduos, preparando-os para se tornarem sucessores, o que é claramente percebido na gestão atual da Drogaria Araujo e nas falas dos entrevistados.

Alguns sujeitos de pesquisa reconhecem que todo esse processo é uma construção própria, na medida em que cada um deles teve que conquistar seu espaço, como também a confiança de seus pais, que os localizaram desde cedo como prováveis herdeiros-sucessores, o que acaba por conferir a todo o processo um caráter natural. Observa-se, contudo, que o sucessor não questiona a sua colocação nesse mundo, o que coloca uma questão: será que o mundo interiorizado por esse herdeiro na socialização primária está tão entrincheirado na sua consciência que as 
realidades interiorizadas na socialização secundária não conseguem se tornar fortes o suficiente para reduzir a relevância da socialização primária? Ou os espaços de socialização secundária desse herdeiro não lhe apresentaram outras realidades, pelo fato de estar sempre presente a empresa da família? Em outras palavras, parece relevante tentarmos compreender se a socialização primária constitui, efetivamente, o espaço privilegiado da socialização, como sustentam Berger e Luckmann (2004), ou se os espaços de socialização primária e secundária são os mesmos - a empresa $e$ a família - e, por essa razão, não lhe apresentaram realidades assim tão diferentes. Pode-se perceber que a socialização primária se mostra sólida a ponto de o indivíduo reconhecer tal construção, mas ele não cogita realizar uma reconstrução da sua própria vida, reafirmando a naturalização da realidade conforme ela lhe foi apresentada. Como ambos os processos de socialização - a primária e a secundária - se dão nos espaços comuns da empresa familiar, percebe-se que sua força na constituição do sujeito herdeiro e sucessor é muito forte.

A partir deste trabalho foi possível traçar, para o caso estudado, o percurso da socialização dos herdeiros sucessores, bem como perceber como esse processo pode se apresentar como um desafio para as famílias que buscam construir a sucessão entre gerações. Dessa forma, os processos de socializações primária e secundária, aos quais os membros da família foram expostos, acabam por se desdobrar em um verdadeiro planejamento tácito do processo sucessório em empresas familiares.

\section{REFERÊNCIAS}

BARDIN, Laurence. Análise de conteúdo. Lisboa: Edições 70, 1977. 229p.

BERGER, Peter L.; LUCKMANN, Thomas. A construção social da realidade: tratado de sociologia do conhecimento, 24. ed. Petrópolis: Vozes, 2004. 248 p.

BORGES, Alex Fernando; LESCURA, Carolina; OLIVEIRA, Janete Lara. O campo de pesquisas sobre empresas familiares no Brasil: análise da produção científica no período 1997-2009. Organização e Sociedade, Salvador, v. 19, n. 61, p. 315-332, abr.-jun. 2012.

CHITTOOR, Raveendra; DAS, Ranjan. Professionalization of management and sucession performance: a vital linkage. Family Business Review, New York, v. 20, n. 1, p. 65-80, mar. 2007. Family Firm Institute, Inc.

DAVEL, Eduardo; COLBARI, Antônia. Organizações familiares: por uma introdução a sua tradição, contemporaneidade e multidisciplinaridade.

Organização e Sociedade, Salvador, v. 7, n. 18, p. 45-64, maio-jul. 2000.

DAVEL, Eduardo; COLBARI, Antônia. Pesquisas sobre organizações familiares: instigações e contribuições. In: XXVII ENCONTRO DA ASSOCIAÇÃO NACIONAL DE PÓS-GRADUAÇÃO EM ADMINISTRAÇÃO, 27, 2003, Atibaia/SP. Anais... São Paulo: ENANPAD, 2003.

DENZIN, Norman K; LINCOLN, Yvonna S. Introdução: a disciplina e pratica da pesquisa qualitativa. In: DENZIN, Norman K; LINCOLN, Yvonaa S. Planejamento da pesquisa qualitativa: teorias e abordagens. 2. ed. Porto Alegre: Artmed Bookman, 2006, p.15-47.

\section{DROGARIA ARAUJO. Uma história dentro da}

história: celebração do centenário da Drogaria Araujo. [s.n] 2007

ENGELS, F. A origem da família, da propriedade privada e do estado. Rio de Janeiro: Civilização Brasileira, 1975. 
LAMBRECHT, Johan. Multigenerational transition in family business: a new explanatory model. Family

Business Review, New York, v. 18, n. 4, p. 267-82, Dec.

2005. Family Firm Institute, Inc.

LANSBERG, Ivan. Succeeding generations. Boston:

Harvard Business School Press, 1999.

LEONE, Nilda Maria de Clodoaldo Pinto Guerra.

Sucessão em empresa familiar: preparando as mudanças para garantir a sobrevivência no mercado globalizado. São Paulo: Atlas, 2005. 198p.

MACHADO, Hilka Vier; SILVEIRA, Amélia Marianne Hoeltgebaum; GOUVEA, Anna Beatriz Cautela Tvrzska. Significados de sucesso e fracasso nos negócios: o que dizem mulheres empreendedoras. In: ENCONTRO DA ASSOCIAÇÃO NACIONAL DE PÓS-GRADUAÇÃO EM ADMINISTRAÇÃO, 32, 2008, Rio de Janeiro. Anais... Rio de Janeiro: ENANPAD, 2008.

MINAYO, Maria Cecília de Souza. O desafio do conhecimento: pesquisa qualitativa em saúde. São Paulo: Hucitec, 2008.

FRANCO, Maria Laura Puglisi Barbosa. Análise de conteúdo. Brasília, DF: Plano, 2003.

RODRIGUES, Maria Socorro Pereira; LEOPARDI, Maria Tereza. $\mathrm{O}$ método de análise de conteúdo: uma versão para enfermeiros. Fortaleza: Fundação Cearense de Pesquisa e Cultura, 1999.

STAKE, Robert E. Qualitative case studies. In: DEZIN, N. K.; LINCOLN, Y. S. (Ed.). Handbook of qualitative research. London: Sage, 1994, cap 17. Disponível em: <http://books.google.com.br>. Acesso em: 10 nov 2012.

YIN, Robert K. Estudo de caso: planejamento e métodos. Porto Alegre: Bookman, 2005, 212p. 